\title{
A LARGE GALCIFIED LIPOMA OF THE THIGH
}

\author{
Report of a Case \\ P. N. Robson, Newcastle-upon-Tyne, England \\ From the Royal Victoria Infirmary
}

A man aged eighty-one years sought advice for a large swelling of the left thigh; it had been present for twenty-one years. One year after it had first been noticed, the tumour was excised, but there was no record of its nature. The swelling recurred a year later and became larger gradually. During the five years immediately previous, growth had been more rapid, with extension into the popliteal region; more recently still there had been pain.

Examination-There was a large mass on the front of the thigh and extending round the lateral aspect to the popliteal fossa (Fig. 1). It reached from the upper third of the thigh to

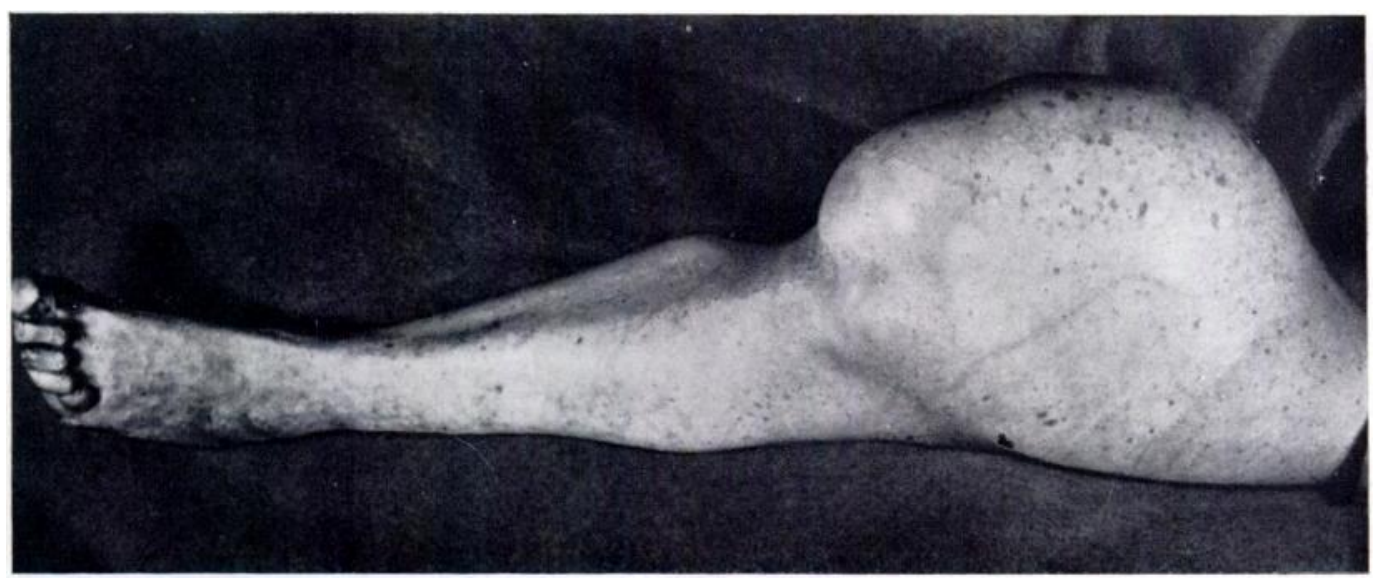

FIG. 1

The pre-operative photograph.

the level of the knee joint. There was a healed scar over the lower part of the tumour, which had displaced the patella forward. Many dilated veins were seen over the swelling, and a fluctuant area could be detected in its upper part. The mass was not attached to skin or to bone. Hip movements were normal but flexion of the knee was limited to 60 degrees. The foot was cold and pale, and the peripheral pulses almost impalpable. By contrast the right leg and its arterial pulses were normal.

Radiographs showed a large soft tissue swelling round the lower two-thirds of the femur, with areas of calcification (Fig. 2). There was no evidence of active bone formation or destruction but there was a suggestion of pressure atrophy of the cortex of the femur just above the medial condyle (Fig. 3). The radiographic appearances were those of calcification in a benign tumour such as a lipoma. Radiographs of the chest showed atheromatous changes in the aorta but no evidence of active pulmonary or mediastinal change.

No immediate treatment was advised. Three months later, however, there was venous congestion and oedema of the limb below the swelling, with early ulceration at the base of the fifth toe. Pulsation in the posterior tibial and dorsalis pedis arteries could not be felt. 
Amputation was performed just above the swelling. The stump healed by first intention, and six months later the patient is alive and well.

Pathological examination showed a lipoma, weighing 5,200 grammes and measuring 18 centimetres in diameter. The tumour contained many areas of calcification from 2 to 5 centimetres in diameter, and numerous small cystic spaces. There was no evidence of malignant change and the bone of the femur appeared normal.

Comment-It seems certain that the tumour was a lipoma which had recurred after incomplete removal twenty years previously. The two features of particular interest were the extensive areas of calcification in the tumour and the vascular obstruction it caused. Calcification in a

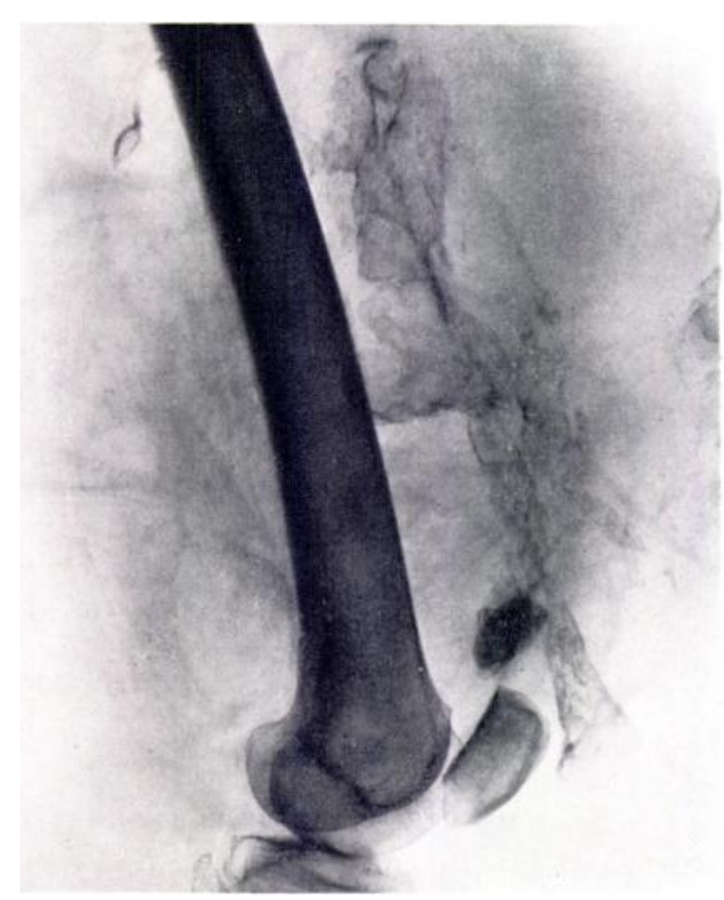

FIci. 2

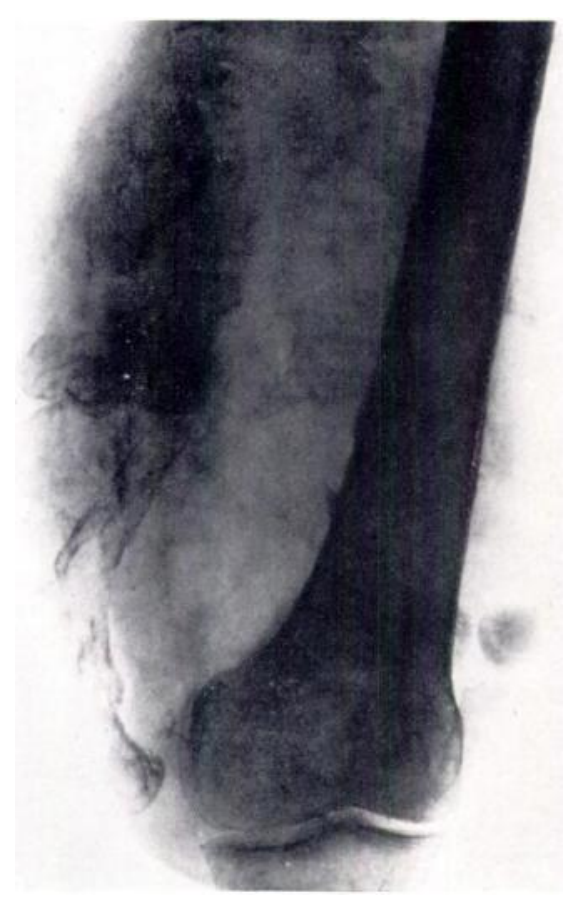

Fic. 3

Figure 2-The lateral radiograph. Note the displacement of the patella. Figure 3 - The antero-posterior radiograph. Note the suggestion of pressure atrophy of the lower femoral shaft.

lipoma was described by Virchow (quoted by Aird 1949) under the term lipoma petrificum ossificans. Infiltrating lipomas of the posterior tibial region have been reported by Regan, Bickel and Broders (1946) but calcification was not observed. In one of their patients the tumour had recurred after removal.

I am indebted to Mr John Brumwell for permission to publish this case, and to I)r J. H. Middlemiss for the radiological report.

\section{REFERENCFS}

Regan, J. M., Bickel, W. H., and Broners, A. ('. (1946): Infiltrating benign lipomas of the extremities. l'roceedings of the staff Meetings of the Mayo Clinic, $21,75$.

Virchow-Quoted by AIRn, I. (1949) in A Companion in surgical studies. Edinburgh: E. \& S. Livingstone I.td. 79 . 